Subscriber access provided by Caltech Library Services

\title{
Article
}

\section{In Situ Catalyst Modification in Atom Transfer Radical Reactions with Ruthenium Benzylidene Complexes}

Juneyoung Lee, Jessica M. Grandner, Keary M. Engle, K. N. Houk, and Robert H. Grubbs

J. Am. Chem. Soc., Just Accepted Manuscript • DOI: 10.1021/jacs.6b03767 • Publication Date (Web): 17 May 2016

Downloaded from http://pubs.acs.org on May 23, 2016

\section{Just Accepted}

"Just Accepted" manuscripts have been peer-reviewed and accepted for publication. They are posted online prior to technical editing, formatting for publication and author proofing. The American Chemical Society provides "Just Accepted" as a free service to the research community to expedite the dissemination of scientific material as soon as possible after acceptance. "Just Accepted" manuscripts appear in full in PDF format accompanied by an HTML abstract. "Just Accepted" manuscripts have been fully peer reviewed, but should not be considered the official version of record. They are accessible to all readers and citable by the Digital Object Identifier (DOI®). "Just Accepted" is an optional service offered to authors. Therefore, the "Just Accepted" Web site may not include all articles that will be published in the journal. After a manuscript is technically edited and formatted, it will be removed from the "Just Accepted" Web site and published as an ASAP article. Note that technical editing may introduce minor changes to the manuscript text and/or graphics which could affect content, and all legal disclaimers and ethical guidelines that apply to the journal pertain. ACS cannot be held responsible for errors or consequences arising from the use of information contained in these "Just Accepted" manuscripts. 


\section{INTRODUCTION}

Since the first report of ruthenium-based catalysts in atom transfer radical addition (ATRA, also called Kharasch addition $)^{1}$ and atom transfer radical polymerization (ATRP), ${ }^{2}$ this area of research has attracted widespread interest. ${ }^{3-14}$ Well-defined ruthenium benzylidene complexes, commonly used as olefin metathesis catalysts, have also been reported to catalyze ATRA and ATRP.,15-19 The ability of ruthenium benzylidene complexes to promote two reactions with such markedly different mechanisms has been utilized in various tandem reactions in which olefin metathesis and ATR reactions take place in one pot. ${ }^{20-22}$

Generally speaking, tandem catalysts, which catalyze multiple distinct reactions in one pot, are attractive synthetic tools that can simplify reaction procedures and reduce operational costs. An improved understanding of their mechanism can enable further catalyst development towards new applications. Among the many tandem catalysts that have been reported, ${ }^{23}$ ruthenium benzylidene complexes have been a topic of interest to our research laboratory. For example, our group has reported ring opening metathesis polymerization (ROMP)-ATRP tandem catalysis for the preparation of block copolymers of 1,5-cyclooctadiene and methylmethacrylate (MMA). ${ }^{20}$ Since the ROMP process was more rapid than ATRP, excess $\mathrm{PCy}_{3}$ was added to the reaction and low-strain cycloolefins were employed to suppress the rate of ROMP. Using low-strain cycloolefins and excess phosphine, the rate of ROMP was suppressed to roughly the same rate as ATRP, allowing for productive tandem catalysis. While the mechanism by which ruthenium benzylidenes initiate and catalyze olefin metathesis has been studied in great detail, little is known regarding the mechanism of ATR reactions promoted by these complexes.

Herein, we present our finding regarding the mechanism of these reactions. We have performed kinetic studies of ATRA using various ruthenium benzylidene complexes. Under common ATRA conditions, these complexes were found to rapidly consume a starting material, but not all of them promoted formation of the desired ATRA product. Our experimental results are consistent with a decomposed ruthenium species, rather than the ruthenium benzylidene, as the active ATRA catalyst in this system. These ATRAactive ruthenium complexes were further found to be inactive in olefin metathesis. We have attempted to identify the new ATRAactive ruthenium species. To do this, we employed NMR spectroscopy and X-ray crystallography. Finally, when this collection of ruthenium benzylidene complexes were tested in ATRP, we found that only the complexes that formed highly reactive ATRA catalysts were able to perform controlled polymerization, rather than redoxinitiated free radical polymerization.

\section{EXPERIMENTAL SECTION}

Materials and analytical techniques. All reactions were carried out in dry vials with PTFE-faced silicone septa under an argon (Ar) atmosphere or in a Vacuum Atmospheres Glovebox 
under a nitrogen atmosphere, as specified. All solvents and reagents were purchased from Sigma-Aldrich and used without further purification unless otherwise noted. Fresh ampules of $\mathrm{CDCl}_{3}$ (SigmaAldrich) were used in decomposition experiments of the ruthenium benzylidene catalysts. Complexes 1, 2, 3, 6, and 7 were obtained from Materia, Inc. Complexes 4 and $\mathbf{5}$ were prepared from $\mathbf{2}$ and 3, respectively, following literature procedures. ${ }^{24,25}{ }^{1} \mathrm{H}$ NMR spectra were recorded on one of the following instruments: Varian Mercury $(300 \mathrm{MHz})$, Varian Inova $(500 \mathrm{MHz})$, or Bruker Ascend with Prodigy broadband cryoprobe $(400 \mathrm{MHz})$. Gel permeation chromatography (GPC) was conducted on two Agilent PLgel 10 $\mu \mathrm{m}$ MIXED-BLS $300 \mathrm{~mm} \times 7.5 \mathrm{~mm}$ columns with Agilent P260 series pump and autosampler with Wyatt Dawn Heleos-II multiangle static light scattering detector and Optilab T-rEX differential refractive index detector with THF as an eluent.

General procedure for ATRA catalyzed by ruthenium benzylidene complexes. To an $8 \mathrm{~mL}$ vial with silicone septum cap equipped with a magnetic stir bar, complex $1\left(62 \mathrm{mg}, 0.75 \times 10^{-1}\right.$ mmol), MMA (106.84 $\left.\mu \mathrm{L}, 9.99 \times 10^{-1} \mathrm{mmol}\right)$, and $\mathrm{CHCl}_{3}(0.8 \mathrm{~mL}$. $9.98 \mathrm{mmol})$ were added. Anisole $\left(10 \mu \mathrm{L}, 9.20 \times 10^{-2} \mathrm{mmol}\right)$ was added as an internal standard. The solution was degassed with Ar (g) for $10 \mathrm{~min}$, and the reaction was initialized by immersing the reaction vessel into an oil bath preheated to the specified temperature $\left(65^{\circ} \mathrm{C}\right.$ or $\left.40{ }^{\circ} \mathrm{C}\right)$. The reaction was kept under $\mathrm{Ar}(\mathrm{g})$, and aliquots were removed at predetermined time points and analyzed by ${ }^{1} \mathrm{H}$ NMR to monitor reaction progress over time. After $2 \mathrm{~h}$, the solution was precipitated into petroleum ether and filtered to remove precipitated catalyst. Solvent and unreacted MMA were dried using a rotary evaporator. The yield of the product was calculated based on integration of ${ }^{1} \mathrm{H}$ NMR resonances at $6.01 \mathrm{ppm}\left(-\mathrm{CCl}_{2} \mathrm{H}\right.$ from the product) and $1.84 \mathrm{ppm}\left(-\mathrm{CH}_{3}\right.$ from the product and byproducts). All of the ATRA reactions in this paper were performed following this general procedure using the same molar ratio of [catalyst $]:[\mathrm{MMA}]:\left[\mathrm{CHCl}_{3}\right]$.

Decomposition study of ruthenium benzylidene complexes. Inside the glovebox, an NMR tube was charged with the ruthenium complex and $\mathrm{CDCl}_{3}$ in the same molar ratio as specified in the general ATRA procedure. The NMR tube was capped with a septum, removed from the glovebox, and heated to $65^{\circ} \mathrm{C}$. ${ }^{1} \mathrm{H}$ NMR spectra were collected at predetermined time points, and the integral of the benzylidene resonance $\left(16-20 \mathrm{ppm},{ }^{1} \mathrm{H}\right)$ was plotted as a function of time.

General procedure for ATRA catalyzed by activated ruthenium complexes. To an $8 \mathrm{~mL}$ vial with silicone septum cap equipped with a magnetic stir bar, complex $1\left(62 \mathrm{mg}, 0.75 \times 10^{-1}\right.$ $\mathrm{mmol})$, anisole $\left(10 \mu \mathrm{L}, 9.20 \times 10^{-2} \mathrm{mmol}\right)$, and $\mathrm{CHCl}_{3}(0.8 \mathrm{~mL}, 9.98$ $\mathrm{mmol}$ ) were added. The solution was degassed with $\mathrm{Ar}(\mathrm{g})$ for 10 min and then heated to $65^{\circ} \mathrm{C}$, until the benzylidene ${ }^{1} \mathrm{H}$ NMR resonance had completely disappeared. The reaction vessel was allowed to cool to room temperature, and freshly degassed MMA (106.84 $\left.\mu \mathrm{L}, 9.99 \times 10^{-1} \mathrm{mmol}\right)$ was added to the solution. The reaction was initialized by immersing the reaction vessel into an oil bath preheated to the specified temperature $\left(65^{\circ} \mathrm{C}\right.$ or $\left.40^{\circ} \mathrm{C}\right)$ and was held under an $\operatorname{Ar}(\mathrm{g})$ atmosphere Aliquots were removed at predetermined time points and analyzed by ${ }^{1} \mathrm{H}$ NMR to monitor reaction progress over time. All of the ATRA reactions in this report with pre-activated ruthenium benzylidene complexes were performed following this general procedure using identical concentrations.
General procedure for ATRA catalyzed by ruthenium benzylidene complexes with 5 equiv $\mathrm{PCy}_{3}$. To an $8 \mathrm{~mL}$ vial with silicone septum cap equipped with a magnetic stir bar, complex 1 (62 mg, $\left.7.53 \times 10^{-2} \mathrm{mmol}\right)$, MMA $(106.84 \mu \mathrm{L}, 9.99 \times 10$ $\left.{ }^{1} \mathrm{mmol}\right)$, anisole $\left(10 \mu \mathrm{L}, 9.20 \times 10^{-2} \mathrm{mmol}\right)$ and $\mathrm{CHCl}_{3}(0.8 \mathrm{~mL}, 9.98$ $\mathrm{mmol})$ were added. $\mathrm{PCy}_{3}\left(105.64 \mathrm{mg}, 3.77 \times 10^{-1} \mathrm{mmol}\right)$ was then added, and the solution was degassed with $\mathrm{Ar}(\mathrm{g})$ for $10 \mathrm{~min}$. The reaction was initialized by immersing the reaction vessel into an oil bath preheated to $65^{\circ} \mathrm{C}$ and was held under an $\mathrm{Ar}(\mathrm{g})$ atmosphere. Aliquots were removed at predetermined time points and analyzed by ${ }^{1} \mathrm{H}$ NMR to monitor reaction progress over time. Experiments with 2 and 3 were performed following this general procedure using identical concentrations and reaction conditions.

RCM catalyzed by 3 and benzylidene-decomposed (ATRA-activated) 3. The reaction was performed following a literature procedure. ${ }^{26}$ Complex $3\left(7.47 \mathrm{mg}, 8.01 \times 10^{-3} \mathrm{mmol}\right)$ was dissolved in degassed $\mathrm{CDCl}_{3}(0.75 \mathrm{~mL})$. For reactions catalyzed by decomposed 3 , the solution was then pre-treated at $65^{\circ} \mathrm{C}$ until the indicated level of benzylidene decay (as monitored by ${ }^{1} \mathrm{H}$ NMR) was observed. The catalyst solution was cool to room temperature, and diethyl diallylmalonate $\left(19.3 \mu \mathrm{L}, 7.98 \times 10^{-2} \mathrm{mmol}\right)$ was added. The reaction mixture was brought to a temperature of $30^{\circ} \mathrm{C}$ for $1 \mathrm{~h}$, after which point an ${ }^{1} \mathrm{H}$ NMR spectrum was collected to calculate olefin conversion.

Crystallization of ATRA-activated 1 with bipy. Complex 1 (62 mg, $\left.0.75 \times 10^{-1} \mathrm{mmol}\right)$ was dissolved into $0.8 \mathrm{~mL}$ of $\mathrm{CHCl}_{3}$ $(0.8 \mathrm{~mL} .9 .98 \mathrm{mmol})$ and was activated by heating at $65^{\circ} \mathrm{C}$ until complete decay of the benzylidene peak in the ${ }^{1} \mathrm{H}$ NMR spectrum was observed. The solvent was removed under vacuum, and the resulting powder was re-dissolved in a minimal amount of DCM, prior to addition of bipy $(58.83 \mathrm{mg}, 0.38 \mathrm{mmol})$. Pentane was slowly added to make a layer above the DCM, and the solution was allowed to stand unperturbed at room temperature until crystals of the complex formed.

ATRA catalyzed by $\mathrm{Ru}(\mathrm{III}) \mathrm{Cl}_{3}$ and $\mathrm{PCy}_{3}$ complex. $\mathrm{MeOH}(0.8 \mathrm{~mL})$ was added to $\mathrm{Ru}(\mathrm{III}) \mathrm{Cl}_{3}\left(15.54 \mathrm{mg}, 0.75 \times 10^{-1}\right.$ $\mathrm{mmol})$ and $\mathrm{PCy}_{3}\left(42.02 \mathrm{mg}, 1.50 \times 10^{-1} \mathrm{mmol}\right)$, and the reaction mixture was heated to reflux overnight. The solvent was removed under vacuum. Benzene was added, and the solution was filtered through glass pipette with kimwipe plug. The filterate was again concentrated under vacuum to give a dried powder. To this solid, were added MMA $\left(106.84 \mu \mathrm{L}, 9.99 \times 10^{-1} \mathrm{mmol}\right)$ and $0.8 \mathrm{~mL}$ of $\mathrm{CHCl}_{3}(0.8 \mathrm{~mL} .9 .98 \mathrm{mmol})$, followed by anisole $\left(10 \mu \mathrm{L}, 9.20 \times 10^{-2}\right.$ $\mathrm{mmol}$ ) as an internal standard. The solution was degassed with $\mathrm{Ar}$ (g) for $10 \mathrm{~min}$, and the reaction was initialized by immersing the reaction vessel into an oil bath preheated to $65^{\circ} \mathrm{C}$.

ATRP catalyzed by ruthenium benzylidene complexes. To an $8 \mathrm{~mL}$ vial with silicone septum cap equipped with a magnetic stir bar, ethyl $\alpha$-bromoisobutyrate $\left(10 \mu \mathrm{L}, 6.81 \times 10^{-5} \mathrm{mmol}\right)$, MMA $\left(1.46 \mathrm{~mL}, 1.36 \times 10^{-2} \mathrm{mmol}\right)$, and complex 1 (56.07 mg, $6.81 \times 10^{-5}$ mmol) were added. Toluene $(681 \mu \mathrm{L})$ and anisole $(10 \mu \mathrm{L})$ were added as the solvent and internal standard, respectively. The solution was degassed with $\mathrm{Ar}(\mathrm{g})$ for $10 \mathrm{~min}$, and the reaction was initialized by immersing the reaction vessel into an oil bath preheated to $85{ }^{\circ} \mathrm{C}$. Aliquots were removed at predetermined time points and analyzed by ${ }^{1} \mathrm{H}$ NMR and GPC to monitor, MMA conversion, $M_{n}$, and dispersity ( $Đ$ ) over time. All of the ATRP reactions in this report were performed following this same general procedure under identical reaction conditions. 


\section{RESULTS AND DISCUSSION}

This investigation commenced by examining reaction kinetics of ATRA with a series of ruthenium benzylidenes commonly employed in olefin metathesis (Chart 1). All of these complexes have been previously reported to catalyze olefin metathesis, and 1 has been shown to be effective in ATR reactions. ${ }^{9,19}$

Chart 1 . Ruthenium benzylidene complexes.<smiles>Cc1cc(C)cc(N2CCN(c3cc(C)cc(C)c3C)C2[R](Cl)(Cl)C=Cc2ccccc2)c1</smiles>

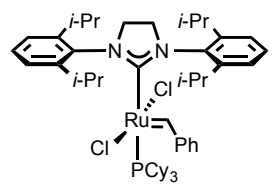

1

2

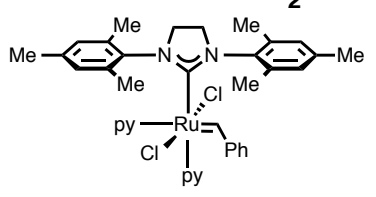

4
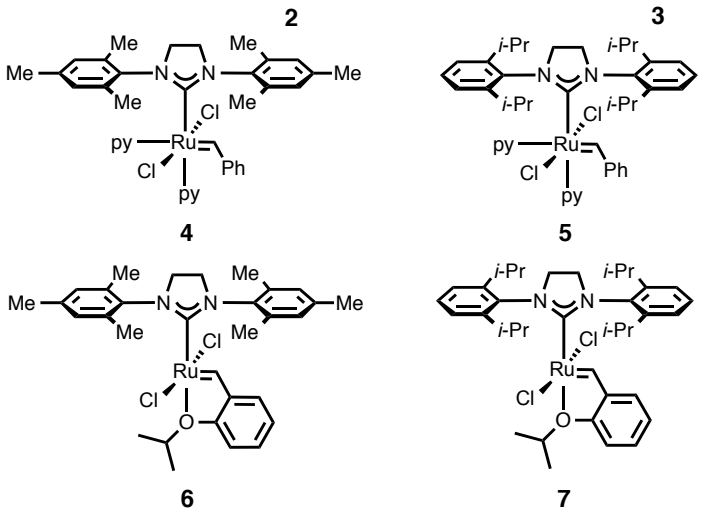

Scheme 1. ATRA of MMA catalyzed by ruthenium benzylidenes or activated ruthenium complexes.

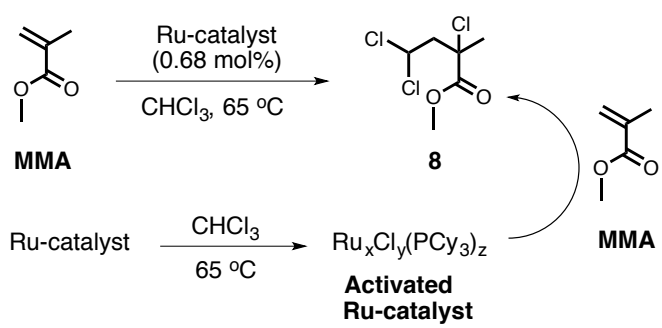

$[\mathrm{MMA}]:\left[\mathrm{CHCl}_{3}\right]:[$ catalyst $]=1: 10: 0.075$

For ATRA, methyl methacrylate (MMA) was employed as a model substrate due to its well-established reactivity in ATRA and ATRP. Chloroform $\left(\mathrm{CHCl}_{3}\right)$ was chosen as the coupling partner and reaction solvent since ATRA using this halogen donor has been studied extensively (Scheme 1). Reactions with all of the complexes shown in Chart 1 were monitored over $2 \mathrm{~h}$ by measuring the MMA conversion at pre-determined time points by ${ }^{1} \mathrm{H}$ NMR spectroscopy (Table 1).

Table 1. MMA conversion and product yield of ATRA $(2 \mathrm{~h})$ with different ruthenium benzylidene complexes.

$\begin{array}{ccccc}\text { entry } & \text { Catalyst } & \begin{array}{c}\text { Temp } \\ \left({ }^{\circ} \mathrm{C}\right)\end{array} & \begin{array}{c}\text { MMA Conv } \\ (\%)^{\mathrm{a}}\end{array} & \begin{array}{c}\text { Yield for 8 } \\ (\%)^{\mathrm{b}}\end{array} \\ 1 & \mathbf{1} & 65 & 89 & 89 \\ 2 & \mathbf{2} & 65 & 45 & 7 \\ 3 & \mathbf{3} & 65 & 95 & 94\end{array}$

$\begin{array}{ccccc}4 & \mathbf{4} & 65 & 79 & 61 \\ 5 & \mathbf{5} & 65 & 17 & \sim 0 \\ 6 & \mathbf{6} & 65 & \sim 0 & \sim 0 \\ 7 & \mathbf{7} & 65 & \sim 0 & \sim 0 \\ 8 & \text { Activated } \mathbf{1} & 65 & 97 & 86 \\ 9 & \text { Activated } \mathbf{3} & 65 & 99 & 93 \\ 10 & \text { Activated } \mathbf{4} & 65 & 86 & 68 \\ 11 & \mathbf{1} & 40 & 20 & \sim 1 \\ 12 & \text { Activated } \mathbf{1} & 40 & 41 & 28 \\ 13 & \mathbf{3} & 40 & 32 & \sim 2 \\ 14 & \text { Activated } \mathbf{3} & 40 & 85 & 70 \\ 15 & \mathbf{1}+5 \text { eq PCy } & 65 & 67 & 16 \\ 16 & \mathbf{2}+5 \text { eq PCy } & 65 & 40 & \sim 0 \\ 17 & \mathbf{3}+5 \text { eq } \mathrm{PCy}_{3} & 65 & 69 & \sim 2\end{array}$

${ }^{\mathrm{a}} \mathrm{MMA}$ conversion was calculated from ${ }^{1} \mathrm{H}$ NMR integration using anisole as an internal standard.

${ }^{\mathrm{b}}$ Product yield was calculated from ${ }^{1} \mathrm{H}$ NMR integration, after first removing the ruthenium catalyst by precipitation into petroleum ether.
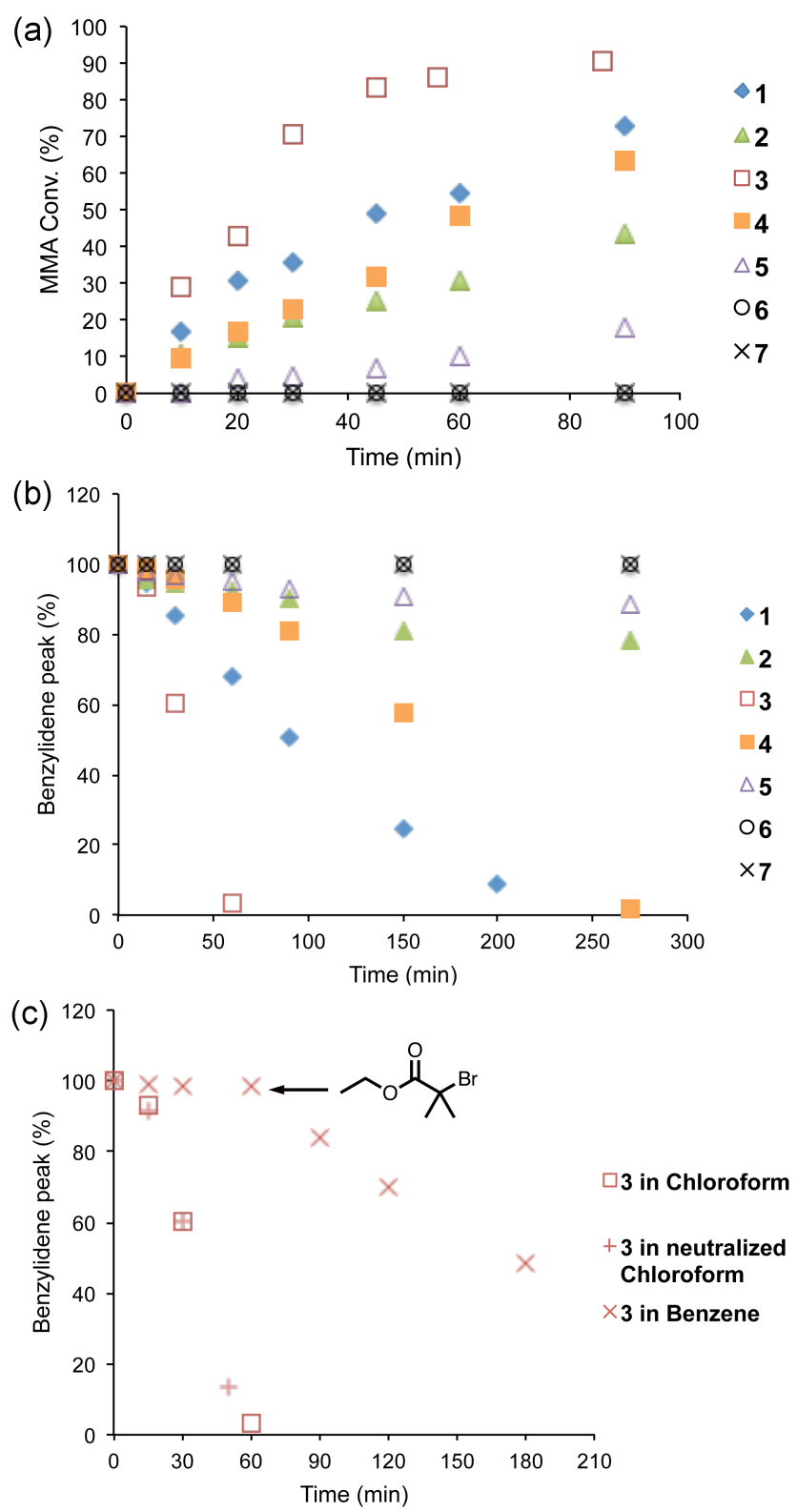
Figure 1. Rate profiles of (a) ATRA promoted by ruthenium benzylidene complexes. Reaction conditions as in Scheme 1. (b) Benzylidene group decay in ${ }^{1} \mathrm{H}$ NMR. Reaction conditions as in Scheme 1 in the absence of MMA. (c) Benzylidene ${ }^{1} \mathrm{H}$ NMR resonance decay in $\mathrm{CDCl}_{3}$, neutralized $\mathrm{CDCl}_{3}$, and $\mathrm{C}_{6} \mathrm{D}_{6}$ with addition of ethyl $\alpha-$ bromoisobutyrate after $1 \mathrm{~h}$. In the neutralized experiment, excess $\mathrm{K}_{2} \mathrm{CO}_{3}$ solid was added to a freshly degassed $\mathrm{CDCl}_{3}$ solution, and the resulting heterogeneous mixture was shaken vigorously prior to heating.

By monitoring MMA conversion over reaction time (Figure 1a and Table 1), it was found that five out of seven ruthenium benzylidene catalysts in the study led to consumption of MMA. Complexes 6 and 7 were found to be unreactive in ATRA. Complex 3 containing a SIPr ligand was the most active, followed in order by $1,4,2$, and 5 . The final yield of the desired product 8 was generally higher with faster ATRA catalysts. For example, with complexes 1 and 3, >99\% of consumed MMA was converted to ATRA product, whereas greater discrepancies between MMA conversion and product yield were observed with 2, 4, and 5. In these cases, MMA may have been consumed in undesired oligomerization/polymerization, a well-known side reaction of ATRA. Notably, no relationship between metathesis activity (or metathesis initiation rate) and ATR rate was observed within this series.

Density functional theory (DFT) calculations were performed assuming a general mechanistic paradigm involving inner-sphere electron transfer from an intact ruthenium benzylidene moiety to homolyze the carbon-halogen bond (Figure S1). However, predicted relative catalyst activities from computed $\Delta \mathrm{G}_{\mathrm{rxn}}$ for this reaction with complexes 1-7 were not in agreement with the empirically observed reactivity trend. Additionally, the $\Delta \mathrm{G}_{\mathrm{rxn}}$ values for the halogen abstraction step with most complexes were too endergonic for effective catalysis. This inconsistency prompted us to consider the stability of complexes 1-7 under the reaction conditions.

Solutions of each complex in $\mathrm{CDCl}_{3}$ without MMA were prepared at the same concentration used in the ATRA experiments. The diagnostic benzylidene proton peak was monitored by ${ }^{1} \mathrm{H}$ NMR $(16-20 \mathrm{ppm})$ over time at the reaction temperature $\left(65^{\circ} \mathrm{C}\right)$. Most of the catalysts were unstable in $\mathrm{CDCl}_{3}$, as evidenced by the disappearance of the benzylidene peak and appearance of new proton resonances far upfield of the benzylidene region. Complexes 6 and 7 were stable for $>4 \mathrm{~h}$ under these conditions (Figure $1 \mathrm{~b}$, Figures S2-S12). This decomposition process was found to be highly temperature- and solvent-dependent. For example, with catalyst 4, no appreciable benzylidene decay was observed at a slightly reduced temperature of $55^{\circ} \mathrm{C}$ for over $4 \mathrm{~h}$. Complex 3 showed rapid benzylidene decay in $\mathrm{CDCl}_{3}$ but did not show any benzylidene decay in $\mathrm{C}_{6} \mathrm{D}_{6}$ until subsequent addition of an alkyl halide (Figure 1c). This indicates that the alkyl halide triggers benzylidene decomposition. Furthermore, complex 3 exhibited a nearly identical benzylidene decay profile in $\mathrm{CDCl}_{3}$ containing added $\mathrm{K}_{2} \mathrm{CO}_{3}$. These results are consistent with the alkyl halide, rather than heat or trace $\mathrm{HCl}$, as the component that drives benzylidene decomposition. Strikingly, the order of benzylidene decay rate in these stoichiometric experiments was the same order as MMA conversion in catalytic ATRA (Figures $1 \mathrm{a}$ and $\mathrm{b}$ ). The correlation between benzylidene decay rate and ATRA rate prompted us to examine the extent to which the newly formed ruthenium species are active participants in ATRA reaction.
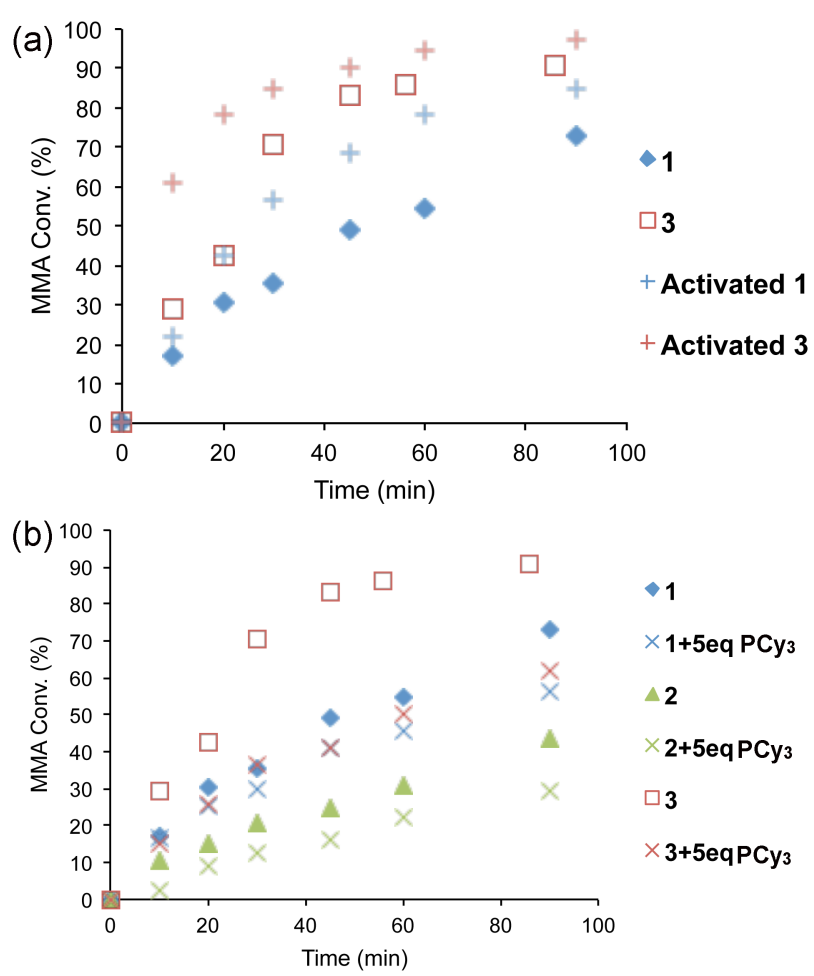

Figure 2. (a) Kinetic study of ATRA of MMA catalyzed by 1, 3, and their activated analogs (b) Effect of adding $\mathrm{PCy}_{3}$ ( 5 equiv) to ATRA catalyzed by 1,2 , and 3 . Reaction condition same as in Scheme 1.

To this end, the reactivity of the benzylidene-decomposed ruthenium species, formed from pre-treatment of 1,3 , and 4 in $\mathrm{CHCl}_{3}$, was investigated. First, solutions of these catalysts in $\mathrm{CHCl}_{3}$ were heated at $65{ }^{\circ} \mathrm{C}$ under $\mathrm{Ar}(\mathrm{g})$ in the absence of MMA until no benzylidene peak was observed in the ${ }^{1} \mathrm{H}$ NMR spectrum. MMA was added, and reaction progress was monitored (Scheme 1). As shown in Table 1 and Figure 2a, the activated ruthenium complexes demonstrated faster rates, providing equally high yield of the ATRA product. Given the pronounced temperature dependence of the stoichiometric benzylidene decay reactions, we next sought to determine the temperature dependence of ATRA reactivity. When ATRA reactions were run with 1 and 3 at $40{ }^{\circ} \mathrm{C}$, where no benzylidene decay was observed, MMA consumption proceeded slowly and only trace product formation was observed. In contrast, preactivated, benzylidene-decayed 1 and 3 exhibited faster rate and provided greater product yields even at $40^{\circ} \mathrm{C}$ (Table 1$)$.

The data shown above indicate a reaction pathway for ATRA in which the ruthenium benzylidene is converted into one or more new ATRA-active ruthenium species under ATRA conditions. When activated, the new species exhibit superior reactivity in ATRA compared to the parent complexes, even at lower temperature. As is typical in ATR reactions, trials performed under our standard conditions were inhibited by $\mathrm{O}_{2}$. Consistent with this observation, the newly formed ruthenium species were found to be air-sensitive and were unreactive in ATRA after exposure to air.

The effect of excess phosphine ligand in catalytic ATRA was also studied. The addition of tricyclohexylphosphine $\left(\mathrm{PCy}_{3}, 5\right.$ equiv 
relative to catalyst) to solutions of the complexes altered the benzylidene decomposition trends (Figure S13). With complexes 1 and 2, the presence of additional $\mathrm{PCy}_{3}$ increased the rate of benzylidene decay. However, complex $\mathbf{3}$ showed slower decay than 1 and 2 under the same conditions. The origins of these effects are still under investigation. The rates of catalytic ATRA reactions with additional $\mathrm{PC}_{3}$ using 1 and 2 were slightly inhibited by excess PCy. The reaction with 3 became substantially slower, and the overall product yield was significantly reduced in all cases (Table 1 and Figure 2b).

Scheme 2. RCM catalyzed by 3 and benzylidenedecomposed ATRA-activated 3.

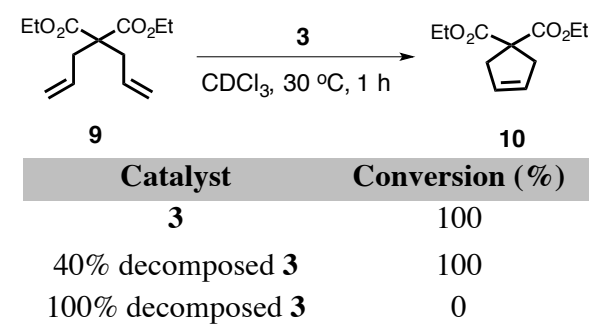

The identity of the in situ generated ruthenium species was explored further. Complex 3 was decomposed in $\mathrm{CDCl}_{3}$ to $40 \%$ completion and $100 \%$ completion (as measured by benzylidene ${ }^{1} \mathrm{H}$ NMR signal). It was found that an ATRA-activated sample of $\mathbf{3}$ with completely decayed benzylidene was inactive in ring-closing metathesis (RCM) of diethyl diallylmalonate (9), a highly reactive RCM substrate with complexes 1-7 (Scheme 2). In contrast, samples of untreated 3 and $40 \%$-benzylidene-decayed 3 catalyzed RCM with 9, providing $100 \%$ conversion to 10 after $1 \mathrm{~h}$. These results, in conjunction with the ${ }^{1} \mathrm{H}$ NMR data, prove that the ATRA-active ruthenium species does not contain a benzylidene/alkylidene moiety.

To gain more information regarding the structure of the ATRAactive species, we next turned to NMR spectroscopy and X-ray crystallography. As discussed above, upon decomposition of complexes 1 and 3 in $\mathrm{CDCl}_{3}$ at $65{ }^{\circ} \mathrm{C}$, the ${ }^{1} \mathrm{H}$ and ${ }^{13} \mathrm{C}$ NMR spectra revealed that the benzylidene moiety had fully dissociated. In the ${ }^{31} \mathrm{P}$ NMR spectra of ATRA-activated $\mathbf{1}$ and 3, a substantial downfield shift of the major phosphine resonance was observed. In both cases, a major phosphine resonance at $108.10 \mathrm{ppm}$ appeared upon decomposition (Figure S4 and Figure S8). This peak is in an unusual region of the ${ }^{31} \mathrm{P}$ spectrum, and we suspect that it could represent the corresponding dichlorophosphonium salt. ${ }^{27} \mathrm{The}^{31} \mathrm{P}$ NMR results along with the data from excess $\mathrm{PCy}_{3}$ experiments shown above (Table 1 and Figure $2 \mathrm{~b}$ ) with 1 and 3 , are consistent with a mechanism in which $\mathrm{PCy}_{3}$ is partially or fully dissociated from the ruthenium center in the active form of the catalysts.

In addition to NMR spectroscopy, we have attempted to obtain single crystals of ATRA-activated ruthenium complexes 1 and 3 that would be suitable for X-ray diffraction. Despite numerous attempts, we were unable to grow suitable crystals directly from the decomposed solutions. However, after extensive experimentation we found that the addition of 2,2'-bipyridine (bipy, 5 equiv) to a solution of ATRA-activated 1 led to formation of a new species, $\mathrm{Ru}(\mathrm{II}) \mathrm{Cl}\left(\mathrm{PCy}_{3}\right)(\text { bipy })_{2} \mathrm{Cl}^{-}$, which we were able to crystallize and characterize by X-ray diffraction (Figure 3). Interestingly preliminary X-ray crystal structure data of the analogous experiment with activated 3 allowed tentative identification of another new complex, $\mathrm{Ru}(\mathrm{III}) \mathrm{Cl}_{3}\left(\mathrm{PCy}_{3}\right)$ (bipy) (data not shown). In both cases, addition of bipy resulted in an upfield shift of the phosphine peak from $108.10 \mathrm{ppm}$ (activated 1 and activated 3 ) to $49.80 \mathrm{ppm}$ (Figure S4 and Figure S8). Moreover, during an attempt to obtain an Xray crystal structure of activated 3 , we instead isolated and characterized the SIPr $\cdot \mathrm{HCl}$ salt. In a separate experiment, when 3 was exposed to ethyl $\alpha$-bromoisobutyrate in $\mathrm{C}_{6} \mathrm{D}_{6}$ (Figure 1c), we were able to obtain colorless crystal from this reaction mixture, which turned out to be the SIPr·HBr salt. Both of these results suggest that the NHC ligands are labile under these reaction conditions.

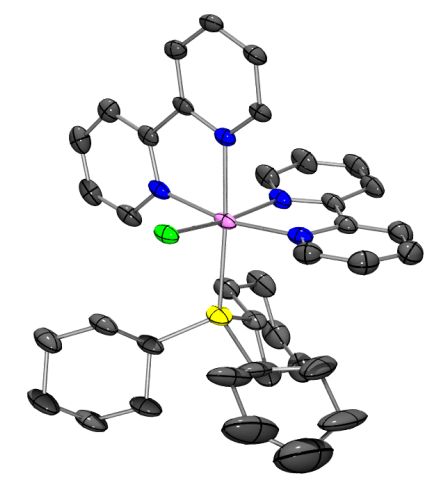

0

Figure 3. X-ray crystal structure of $\mathrm{Ru}(\mathrm{II}) \mathrm{Cl}\left(\mathrm{PCy}_{3}\right)(\text { bipy })_{2} \mathrm{Cl}^{-}$ formed from addition of bipy to ATRA-activated 1. Hydrogen atoms and solvent molecules were omitted for clarity. Pink: $\mathrm{Ru}$, Gray: C, Yellow: P, Blue: N, Green: Cl (CCDC 1473173).

Combining the insights from all of these experiments, we now suspect that the original ruthenium benzylidene complexes decompose under common ATRA reaction condition $\left(65^{\circ} \mathrm{C}\right.$ in $\left.\mathrm{CHCl}_{3}\right)$ through complete dissociation of all L-type ligands (benzylidene, $\mathrm{PC}_{3}$, and $\mathrm{NHC}$ ) from the ruthenium metal center. We propose that a simple ruthenium chloride complex, such as $\mathrm{Ru}(\mathrm{III}) \mathrm{Cl}_{3}$ or $\mathrm{Ru}(\mathrm{II}) \mathrm{Cl}_{2}$ or $\mathrm{Ru}_{\mathrm{x}} \mathrm{Cl}_{\mathrm{y}}$ cluster, possibly containing one or more bound phosphine ligands, is the actual ATRA-active species. To explore possibility further, we attempted to perform ATRA with $\mathrm{Ru}(\mathrm{III}) \mathrm{Cl}_{3}$, which we found to be completely insoluble in $\mathrm{CHCl}_{3}$ even upon addition of MMA. To solubilize this complex, $\mathrm{Ru}(\mathrm{III}) \mathrm{Cl}_{3}$ was refluxed with $\mathrm{PCy}_{3}$ in $\mathrm{MeOH}$ overnight, concentrated in vacuo, suspended in benzene, filtered, washed with benzene and dried. The resulting ruthenium complex, presumably $\mathrm{RuCl}_{3}\left(\mathrm{PCy}_{3}\right)_{n}$, was soluble in $\mathrm{CHCl}_{3}$ and successfully converted MMA to the ATRA product with $96 \%$ MMA conversion and $88 \%$ product yield (Figure S14). Also, the reaction kinetics with $\mathrm{RuCl}_{3}\left(\mathrm{PCy}_{3}\right)_{n}$ were faster than with 3 and were in perfect agreement with ATRA-activated 3. The newly prepared $\mathrm{RuCl}_{3}\left(\mathrm{PCy}_{3}\right)_{n}$ complex, however, did not show the same peaks in the ${ }^{31} \mathrm{P}$ spectrum as activated 1 or activated 3 (108.10 ppm). This experiment confirms that the phosphine peak from $108.10 \mathrm{ppm}$ in ATRA-activated 3 is a byproduct from the catalyst activation process and does not correspond to a ruthenium species that is involved in ATRA reaction. 
(a)

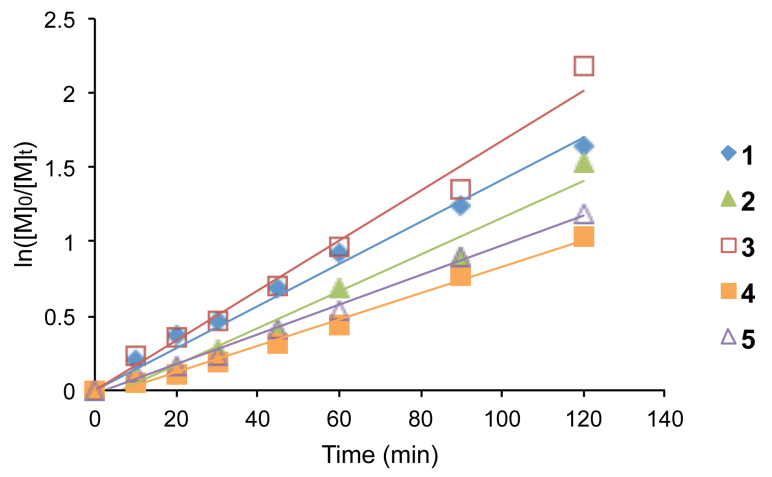

(b)
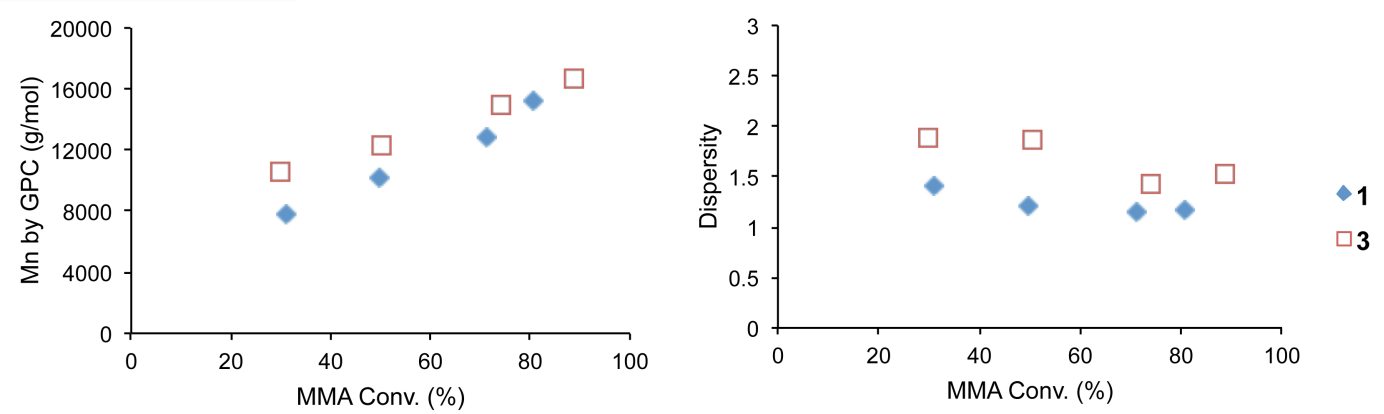

(c)
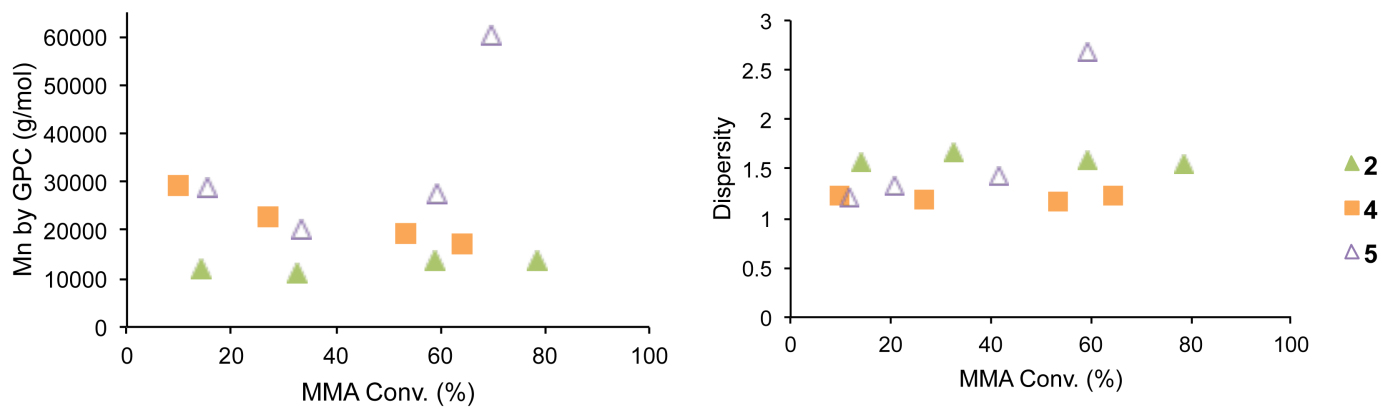

Figure 4. Kinetic studies of ATRP catalyzed by ruthenium benzylidene complexes. (a) $\ln \left([M]_{0} /[M\}_{t}\right)$ over time (b) $M_{n}$ and $Đ$ over MMA conversion with 1 and 3 (c) $M_{n}$ and $Đ$ over MMA conversion with 2, 4, and 5 .

Scheme 3. ATRP of MMA catalyzed by ruthenium benzylidenes.

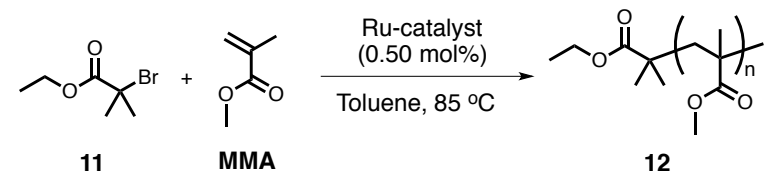

[11] : [MMA] : [catalyst] $=1: 200: 1$

$0.02 \mathrm{M} 11$ in toluene

Lastly, we performed a series of experiments to test whether insights gained from this investigation were relevant to ATRP. ATRP and ATRA have similar mechanisms involving active radicals generated by a reversible redox process of halogenated substrates and transition metal complexes. ${ }^{28}$ In ATRP, a large excess of olefin leads to polymerization rather than a single radical addition. Ruthenium benzylidene complexes 1-5 converted MMA to polymer (Scheme 3 , Figure 4). The order of reaction rates was similar to the previous catalytic ATRA, except that 4 was the slowest in ATRP. However, only 1 and 3 polymerized MMA in a controlled fashion to yield polymers with linear molecular weight increases and low dispersities. Polymerization with 2, 4, and 5 showed constant molecular weight, indicating early termination of the polymer chains and even undesired coupling reactions in the case of 5 . It has been reported that some ruthenium benzylidenes preferentially promote redoxinitiated free radical polymerization over ATRP, ${ }^{18}$ however, no clear explanation has been put forward to rationalize the differences. The present work shows that complexes 1 and 3, which exhibited rapid in situ conversion in $\mathrm{CHCl}_{3}$ with high product yield in ATRA, also promoted efficient ATRP. A well-known side reaction of ATRA is polymerization/oligomerization, which can proceed via redox-initiated free radical polymerization. Thus, the ATRA data can be used to explain which ruthenium benzylidene precatalysts favors ATRP over free radical polymerization.

\section{CONCLUSION}

We have discovered that under ATRA conditions, ruthenium benzylidene complexes are transformed into one or more new ATRAactive, metathesis-inactive ruthenium species, possibly simple $\mathrm{Ru}_{\mathrm{x}} \mathrm{Cl}_{\mathrm{y}}\left(\mathrm{PCy}_{3}\right)_{\mathrm{z}}$ complex. The same complexes that give high yields and minimal competing side reactions in ATRA also promote living ATRP over uncontrolled free radical polymerization. The results of this study showcase the importance of mechanistic inquiry as a 
means of better understanding and ultimately improving tandem catalytic reactions.

\section{ASSOCIATED CONTENT}

\section{Supporting Information}

All of the detailed experimental procedures, NMR spectra, CIF file of crystal data, computational data are available free of charge via the Internet at http://pubs.acs.org.

\section{AUTHOR INFORMATION}

\section{Corresponding Author}

* rhg@caltech.edu

\section{Present Addresses}

$\S$ The Scripps Research Institute, Department of Chemistry, $10550 \mathrm{~N}$. Torrey Pines Rd., La Jolla, CA 92037

\section{ACKNOWLEDGMENT}

The research described was financially supported by the ONR (Award N00014-12-1-0596) and the NIH NIGMS (Award F32GM108145; postdoctoral fellowship to K.M.E.). The authors thank Materia, Inc. for generous donation of catalysts 1, 2, 3, 6, and 7. The authors also thank Dr. Michael Haibach (Grubbs group, Caltech) and Dr. Peter Dornan (Grubbs group, Caltech) for the helpful discussions. Calculations were performed using the NSF funded (OCI-1053575) Extreme Science and Engineering Discovery Environment (XSEDE) and the UCLA Hoffman2 Cluster.

\section{REFERENCES}

(1) Matsumot.H; Nakano, T.; Nagai, Y. Tetrahedron Lett. 1973, 51475150 .

(2) Ando, T.; Kamigaito, M.; Sawamoto, M. Tetrahedron 1997, 53, 15445-15457.

(3) Simal, F.; Wlodarczak, L.; Demonceau, A.; Noels, A. F. Tetrahedron Lett. 2000, 41, 6071-6074.

(4) Simal, F.; Sebille, S.; Demonceau, A.; Noels, A. F.; Nunez, R.; Abad, M.; Teixidor, F.; Vinas, C. Tetrahedron Lett. 2000, 41, 5347-5351.

(5) Simal, F.; Wlodarczak, L.; Demonceau, A.; Noels, A. F. Eur. J. Org. Chem. 2001, 2689-2695.

(6) Tutusaus, O.; Delfosse, S.; Demonceau, A.; Noels, A. F.; Vinas, C.; Teixidor, F. Tetrahedron Lett. 2003, 44, 8421-8425.
(7) Kato, M.; Kamigaito, M.; Sawamoto, M.; Higashimura, T. Macromolecules 1995, 28, 1721-1723.

(8) Kamigaito, M.; Ando, T.; Sawamoto, M. Chem. Rev. 2001, 101, 36893746.

(9) Simal, F.; Demonceau, A.; Noels, A. F. Angew. Chem. Int. Ed. 1999, $38,538-540$.

(10) Matyjaszewski, K.; Xia, J. Chem. Rev. 2001, 101, 2921-2990.

(11) Simal, F.; Jan, D.; Delaude, L.; Demonceau, A.; Spirlet, M. R.; Noels, A. F. Can. J. Chem. 2001, 79, 529-535.

(12) Kamigaito, M.; Watanabe, Y.; Ando, T.; Sawamoto, M. J. Am. Chem. Soc. 2002, 124, 9994-9995.

(13) Opstal, T.; Verpoort, F. New J. Chem. 2003, 27, 257-262.

(14) Camerano, J. A.; Rodrigues, A.-S.; Rominger, F.; Wadepohl, H.; Gade, L. H. Organomet. Chem. 2011, 696, 1425-1431.

(15) Faulkner, J.; Edlin, C. D.; Fengas, D.; Preece, I.; Quayle, P.; Richards, S. N. Tetrahedron Lett. 2005, 46, 2381-2385.

(16) Lee, B. T.; Schrader, T. O.; Martin-Matute, B.; Kauffman, C. R.; Zhang, P.; Snapper, M. L. Tetrahedron 2004, 60, 7391-7396.

(17) Simal, F.; Demonceau, A.; Noels, A. F. Tetrahedron Lett. 1999, 40, 5689-5693.

(18) Simal, F.; Delfosse, S.; Demonceau, A.; Noels, A. F.; Denk, K.; Kohl, F. I.; Weskamp, T.; Herrmann, W. A. Chem. Eur.J. 2002, 8, 3047-3052.

(19) Tallarico, J. A.; Malnick, L. M.; Snapper, M. L. J. Org. Chem. 1999, $64,344-345$

(20) Bielawski, C. W.; Louie, J.; Grubbs, R. H. J. Am. Chem. Soc. 2000, 122, 12872-12873.

(21) Seigal, B. A.; Fajardo, C.; Snapper, M. L. J. Am. Chem. Soc. 2005, 127, 16329-16332.

(22) Borguet, Y.; Sauvage, X.; Zaragoza, G.; Demonceau, A.; Delaude, L. Beilstein J. Org. Chem. 2010, 6, 1167-1173.

(23) Fogg, D. E.; dos Santos, E. N. Coord. Chem. Rev. 2004, 248, 23652379.

(24) Sanford, M. S.; Love, J. A.; Grubbs, R. H. Organometallics 2001, 20, 5314-5318.

(25) Leitao, E. M.; Piers, W. E.; Parvez, M. Can. J. Chem. 2013, 91, 935942.

(26) Ritter, T.; Hejl, A.; Wenzel, A. G.; Funk, T. W.; Grubbs, R. H. Organometallics 2006, 25, 5740-5745.

(27) Shih, W.-C.; Ozerov, O. V. Organometallics 2015, 34, 4591-4597.

(28) Richel, A.; Delfosse, S.; Cremasco, C.; Delaude, L.; Demonceau, A.; Noels, A. F. Tetrahedron Lett. 2003, 44, 6011-6015. 
1

2

3

4

5

6

7

8

9

10

11

12

13

14

15

16

17

18

19

20

21

22

23

24

25

26

27

28

29

30

31

32

33

34

35

36

37

38

39

40

41

42

43

44

45

46

47

48

49

50

51

52

53

54

55

56

57

58

59

60

\section{TOC Figure}

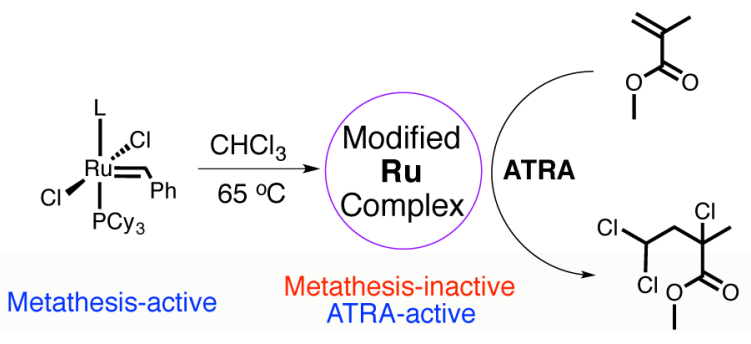

